Review

\title{
Hyperpolarized NMR Probes for Biological Assays
}

\section{Sebastian Meier ${ }^{1, *}$, Pernille R. Jensen ${ }^{2}$, Magnus Karlsson ${ }^{2}$ and Mathilde H. Lerche ${ }^{2, *}$}

1 Carlsberg Laboratory, Gamle Carlsberg Vej 10, 1799 Copenhagen V, Denmark

2 Albeda Research, Gamle Carlsberg Vej 10, 1799 Copenhagen V, Denmark;

E-Mails: pernille.rose.jensen@albeda.dk (P.R.J.); magnus.karlsson@albeda.dk.dk (M.K.)

* Authors to whom correspondence should be addressed;

E-Mails: sebastian.meier@ carlsberglab.dk (S.M.); mathilde.lerche@albeda.dk (M.H.L.);

Tel.: +45-3327-5301 (S.M.); +45-3327-5320 (M.H.L.); Fax: +45-3327-4708 (S.M. \& M.H.L.).

Received: 28 November 2013; in revised form: 20 December 2013 / Accepted: 7 January 2014 /

Published: 16 January 2014

\begin{abstract}
During the last decade, the development of nuclear spin polarization enhanced (hyperpolarized) molecular probes has opened up new opportunities for studying the inner workings of living cells in real time. The hyperpolarized probes are produced ex situ, introduced into biological systems and detected with high sensitivity and contrast against background signals using high resolution NMR spectroscopy. A variety of natural, derivatized and designed hyperpolarized probes has emerged for diverse biological studies including assays of intracellular reaction progression, pathway kinetics, probe uptake and export, $\mathrm{pH}$, redox state, reactive oxygen species, ion concentrations, drug efficacy or oncogenic signaling. These probes are readily used directly under natural conditions in biofluids and are often directly developed and optimized for cellular assays, thus leaving little doubt about their specificity and utility under biologically relevant conditions. Hyperpolarized molecular probes for biological NMR spectroscopy enable the unbiased detection of complex processes by virtue of the high spectral resolution, structural specificity and quantifiability of NMR signals. Here, we provide a survey of strategies used for the selection, design and use of hyperpolarized NMR probes in biological assays, and describe current limitations and developments.
\end{abstract}

Keywords: hyperpolarization; NMR; assays; bioprobes; designed probes; endogenous probes 


\section{Introduction}

Technological and methodological improvements allow for the study of increasingly complex processes and systems, not least for studying the inner workings of living cells [1,2]. Various detection modalities are used to this end, providing complementary advantages and information for probing and labeling cellular metabolites. For example, several small-molecule and genetically encoded fluorescent probes are under examination for their potential to measure steady-state concentrations, enzyme activities and resulting intracellular reaction kinetics [1,3]. Other methods include IR [4], UV-Vis, luminescence, Raman [5] and NMR spectroscopy as well as destructive detection by mass spectrometry [2]. The choice of appropriate methods requires consideration of the ease of use, commercial availability, sensitivity, biocompatibility, selectivity, spatiotemporal resolution, general applicability, non-invasiveness and quantifiability [1].

NMR spectroscopy is a robust, generally applicable and noninvasive method yielding quantifiable and high-resolution spectroscopic data that can distinguish analytes by resolving individual atomic sites. On the other hand, NMR spectroscopy has shortcomings in terms of sensitivity. In addition, the detection of individual atomic sites usually also leads to complex spectra, as a consequence of the overlap of signals of interest with non-informative cosolute and solvent signals. Isotope enrichment of NMR active atoms with low natural abundance, in particular ${ }^{13} \mathrm{C}$ and ${ }^{15} \mathrm{~N}$, has been a means to use NMR active probes that are selectively enhanced over background signals by a factor given by their isotope enrichment. NMR spectroscopy is understood from first principles and the interaction between magnetic moments can be used to enhance otherwise weak signals in a controlled manner by transfer of polarization from spins with high magnetic moments (usually protons and electrons) to nuclear spins with lower magnetic moments (e.g., ${ }^{13} \mathrm{C}$ and ${ }^{15} \mathrm{~N}$ ). During the last decade, a new generation of nuclear magnetic resonance probes has become popular that affords signal improvements relative to spectral noise and biological backgrounds of at least 3-4 orders of magnitude. This review consecutively covers nuclear spin hyperpolarization, assay designs for hyperpolarized NMR probing, emerging strategies and applications using designed and natural probes, current technological developments and future hopes for NMR assays based on hyperpolarized probes and labels. Several excellent reviews have recently described the development of hyperpolarized contrast agents for functional magnetic resonance imaging [6-9], an application area that is therefore not discussed herein.

\section{Hyperpolarization of Molecular Probes}

High-resolution nuclear magnetic resonance (NMR) spectroscopy has established itself as a principal detection modality in a remarkable variety of disciplines [10-12]. In the life sciences, many of these applications rely on the use of NMR for retrieving molecular information in close to natural environments and intact biofluids, often in order to probe molecular recognition events and biocatalysis. A principal shortcoming of NMR spectroscopy has remained its moderate sensitivity owing to the low equilibrium polarization of nuclear spins as defined for spin-1/2 nuclei by:

$$
P_{\mathrm{eq}}=\frac{n^{-}-n^{+}}{n^{-}+n^{+}} \cong \tan h \frac{\gamma \hbar B_{0}}{2 k_{\mathrm{b}} T}
$$


where $n^{-}$and $n^{+}$are the numbers of nuclear spins in the lower and higher energy Zeeman eigenstates, $\gamma \hbar B_{0}$ is the energy gap between the Zeeman eigenstates and $k_{\mathrm{b}} T$ is the thermal energy [13]. The equilibrium nuclear spin determines the fraction of nuclear spins contributing to the detected signal. This fraction remains well below $0.1 \%$ for all nuclear spins at currently available NMR spectrometer fields (Figure 1).

Figure 1. (A) Spin polarizations of electrons ("e"), ${ }^{1} \mathrm{H},{ }^{13} \mathrm{C}$ and ${ }^{15} \mathrm{~N}$ nuclei in a 3.35 Tesla DNP polarizer near liquid helium temperature, compared to spin polarizations of ${ }^{1} \mathrm{H},{ }^{13} \mathrm{C}$ and ${ }^{15} \mathrm{~N}$ in a 14.1 Tesla $(600 \mathrm{MHz})$ spectrometer at $273-373 \mathrm{~K}$. An approach to hyperpolarization is the transfer of electron spin polarization to nuclei near $1.2 \mathrm{~K}$ prior to dissolution of the hyperpolarized sample in hot aqueous buffer; (B) resultant hyperpolarized samples in aqueous solutions achieve spin polarizations $\mathrm{P}$ that are $\sim 3-4$ orders of magnitude enhanced relative to the thermal equilibrium polarization in an NMR spectrometer.

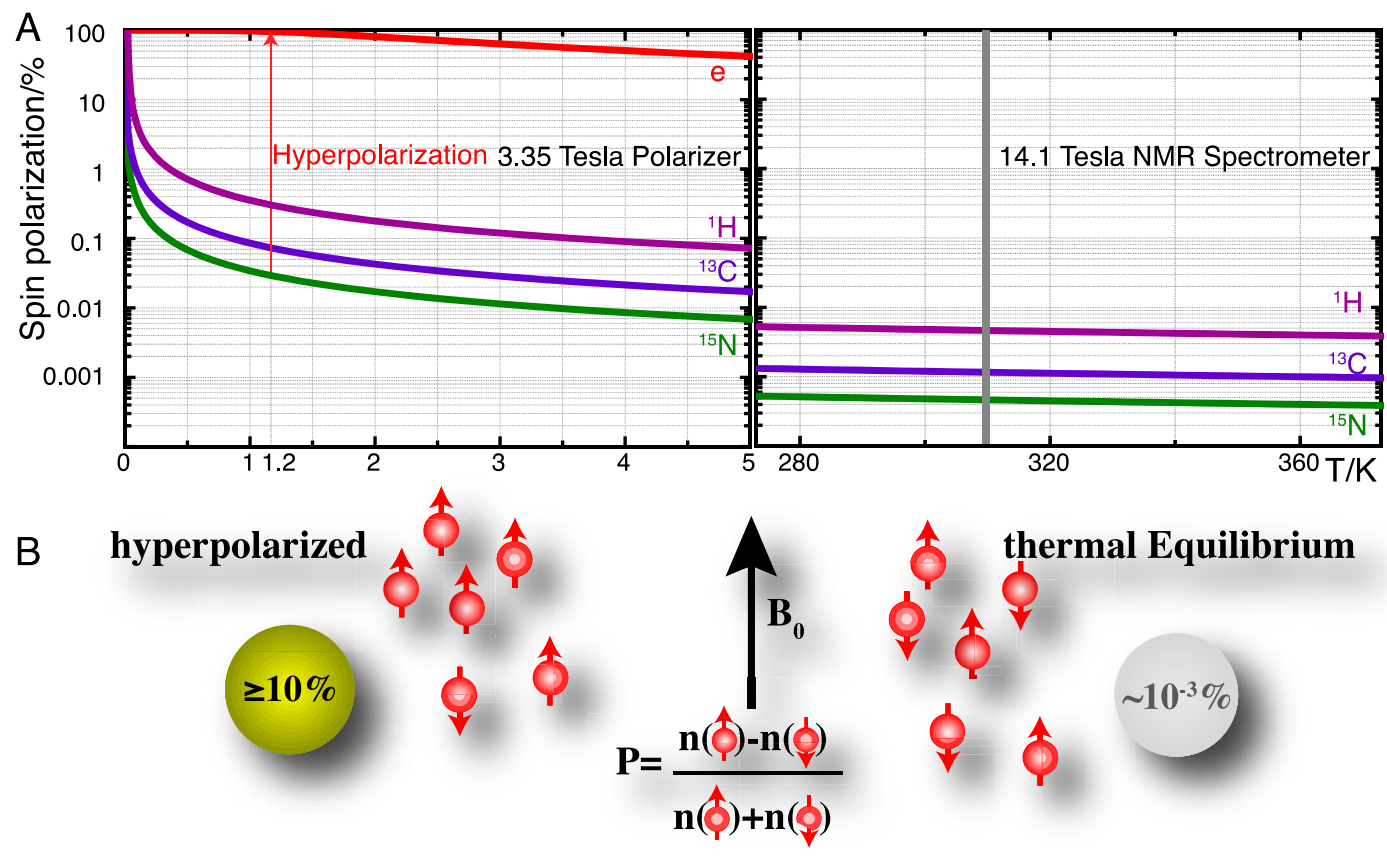

Hyperpolarization strategies, such as parahydrogen induced polarization [14], transfer of photon angular momentum to noble gases by optical pumping $[15,16]$, conversion of rotational energy into nuclear polarization upon cooling (Haupt effect) [17,18] and dynamic nuclear polarization (DNP) [19-21] can redistribute the populations of nuclear spin eigenstates far away from equilibrium. DNP is the technique that is most generally applicable in the production of hyperpolarized molecular probes and the principle of these methods is briefly detailed as follows. DNP hinges on the transfer of electron spin polarization from a free radical to nuclear spins by microwave irradiation [19,22,23]. This transfer is best conducted in amorphous samples that assure the homogenous distribution of electron and nuclear spins. DNP is typically performed at low temperatures $(<1.5 \mathrm{~K})$ and at high magnetic fields $(>3 \mathrm{~T})$ where the electron spin polarization approaches 100\% (Figure 1A). Dedicated instruments for DNP under these conditions achieve solid-state polarizations of NMR active nuclei above 10\% and are commercially available as so-called "polarizers" (http://www.oxford-instruments.com [24]). The DNP approach to hyperpolarization has gained broad chemical and biological relevance due to a dissolution 
setup that harvests a hyperpolarized molecular probe by washing the frozen glass of $\sim 1 \mathrm{~K}$ temperature rapidly out of a polarizer with heated buffer [25]. Hyperpolarization losses during this dissolution step can be kept to a minimum and molecular probes with polarizations enhanced by several orders of magnitude can be produced for use in biological assays at ambient temperature and for detection with high-resolution liquid state NMR spectroscopy. A principal limitation of using hyperpolarized molecular probes is the short hyperpolarization lifetime of seconds to a few minutes for non-protonated sites in small molecules.

Hyperpolarized tracers employ a variety of NMR active nuclei with sufficiently slow hyperpolarization loss (determined by the longitudinal $\mathrm{T}_{1}$ relaxation time of the nucleus) to perform assays on the minute time scale (Table 1). In practice, these probes combine isotope enrichment with hyperpolarization in order to achieve up to $>10^{6}$ fold signal enhancement over non-informative cellular background signals due to the combined (multiplicative) effect of isotope enrichment and hyperpolarization. The generation and detection of hyperpolarized NMR signal is particularly useful for the nuclei in Table 1 [15,16,25-28], as the low magnetogyric ratios relative to ${ }^{1} \mathrm{H}$ leads to small equilibrium polarizations (Figure 1A) and the generation of smaller recorded signal by Faraday induction in the NMR coil (see molar receptivity in Table 1) [29]. At the same time, long relaxation times necessitate long inter-scan recycle delays for some of these nuclei in conventional NMR, thus aggravating their poor utility in conventional NMR detecting nuclear magnetism under conditions of equilibrium spin polarization.

Table 1. Nuclei used in hyperpolarized NMR probes.

\begin{tabular}{cccc}
\hline Nucleus & Spin I & Natural Abundance & Molar Receptivity ${ }^{\text {a rel. to }}{ }^{\mathbf{1}} \mathbf{H}$ \\
\hline${ }^{3} \mathrm{He}$ & 1 & $<<0.1 \%$ & $44.2 \%$ \\
${ }^{6} \mathrm{Li}$ & 1 & $7.6 \%$ & $0.85 \%$ \\
${ }^{13} \mathrm{C}$ & $1 / 2$ & $1.1 \%$ & $1.59 \%$ \\
${ }^{15} \mathrm{~N}$ & $1 / 2$ & $0.4 \%$ & $0.10 \%$ \\
${ }^{19} \mathrm{~F}$ & $1 / 2$ & $100 \%$ & $83.3 \%$ \\
${ }^{29} \mathrm{Si}$ & $1 / 2$ & $4.7 \%$ & $0.08 \%$ \\
${ }^{89} \mathrm{Y}$ & $1 / 2$ & $100 \%$ & $0.01 \%$ \\
${ }^{107} \mathrm{Ag}$ & $1 / 2$ & $51.8 \%$ & $<0.01 \%$ \\
${ }^{109} \mathrm{Ag}$ & $1 / 2$ & $48.2 \%$ & $0.01 \%$ \\
${ }^{129} \mathrm{Xe}$ & $1 / 2$ & $26.4 \%$ & $2.16 \%$ \\
\hline
\end{tabular}

a NMR signal detection in a coil by Faraday induction is proportional to a factor $\left|\gamma^{3}\right| \mathrm{I}(\mathrm{I}+1)$ where $\gamma$ is the magnetogyric ratio; the molar receptivity thus describes the NMR signal generated by identical amounts of nuclear isotopes (i.e., enriched to $100 \%$ ) relative to ${ }^{1} \mathrm{H}[30]$.

Considering the sensitivity limitation of conventional NMR spectroscopy, it is little surprise that technological and methodological advances resulting in increased sensitivity directly increase the scope of NMR spectroscopy in the study of complex systems. As an example, the $\sim 4$-fold sensitivity gain resulting from cryogenically cooled detection systems has greatly facilitated the in-cell study of recombinant or microinjected isotope-enriched proteins [31,32]. Hyperpolarization approaches yielding $10^{3}-10^{4}$-fold sensitivity gains for molecular probes clearly have significant potential for investigating complex molecular systems such as the inner workings of living cells in a time-resolved 
and non-invasive manner. The information content of NMR spectroscopic detection is diverse and includes rapid high-resolution spectroscopic readouts of various NMR parameters such as signal frequency, structural motifs and bound nuclei, rotational correlation time and translational diffusion. Spectral information in conventional and hyperpolarized NMR is adaptable by modulating the timing, frequency, power, duration and phase of electromagnetic excitation pulses.

In the current methodological implementations as described above, hyperpolarized probes are produced ex situ in a first step, which is specifically designed to optimize signal that is detectable in NMR spectroscopic assays (Figure 2). These assays have been used in diverse experiments for the rapid measurement of steady state concentrations, transporter and enzyme activities and kinetic profiles of cellular reactions. An overview of the hitherto employed probes and assays is provided in Table 2. Predictably, this list may change rapidly as a consequence of the generality of DNP approaches for producing a growing suite of small molecular probes [33], the increasing commercial availability (and popularity) of the technology, improved protocols for probe formulations [33-35] and the recent development of increasingly adaptable platforms for the versatile development of novel probes [36-38].

Figure 2. Principle of biological assays using hyperpolarized NMR probes. Hyperpolarization is optimized ex situ and the hyperpolarized probe or label is added to a biomolecule, cell extracts or living cells to conduct biological assays for detection inside an NMR spectrometer.

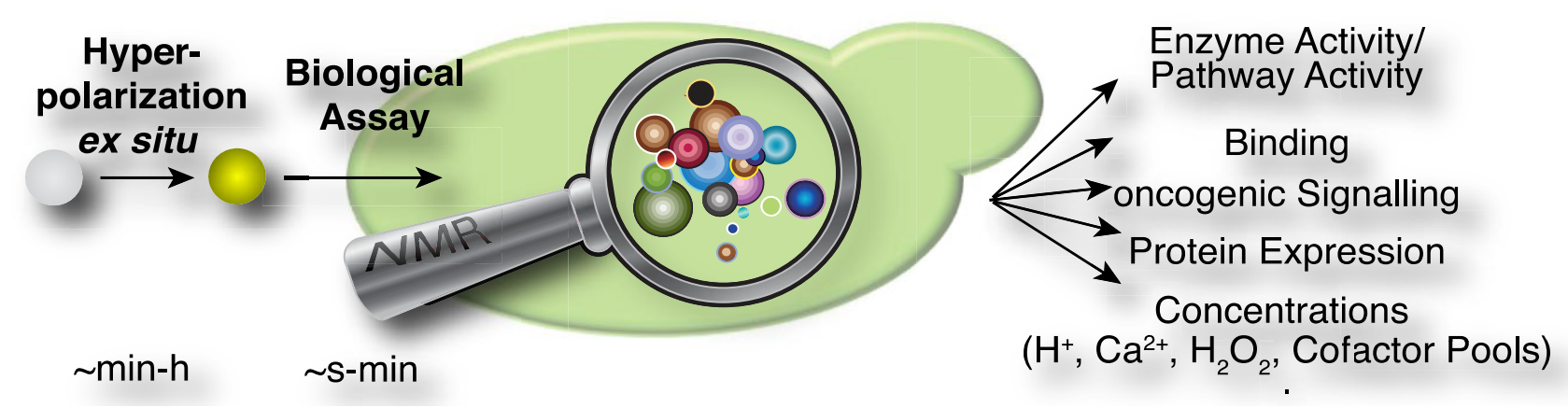

\section{Assay Types}

NMR spectroscopic detection of hyperpolarized molecular probes provides rich and adaptable information from versatile assay platforms. Some viable assay types are sketched in Figure 3 with hyperpolarized probes depicted as small colored shapes. Figure $3 \mathrm{~A}$ indicates an approach taken in the determination of amino acids by "secondary labelling" of amino acids with hyperpolarized $\left[1,1^{\prime}-{ }^{13} \mathrm{C}_{2}\right]$ acetic anhydride [39]. The approach is an adaptation of a chemical derivatization method in conventional NMR at thermal equilibrium. A class of analytes (here amines) is selected from a complex mixture with minimal sample pretreatment by the acetylation with $\left[1,1^{\prime}{ }_{-}^{13} \mathrm{C}_{2}\right]$ acetic anhydride [40]. Upon reaction with different amines, the acetyl label yields resolvable and quantifiable signals for the covalent adducts in thermal and — with improved sensitivity — in hyperpolarized NMR. 
Figure 3. Schematics of different strategies for the use of hyperpolarized labels and probes for NMR spectroscopic biological assays: Hyperpolarized molecules have been used for (A) readout by covalent chemical labeling of analytes; (B) probing of non-covalent binding; (C) the tracking of enzymatic transformations; (D) the design of versatile probe platforms; (E) ratiometric measurements of physicochemical states and (F) interrogating protein expression by probing attached reporter enzymes.
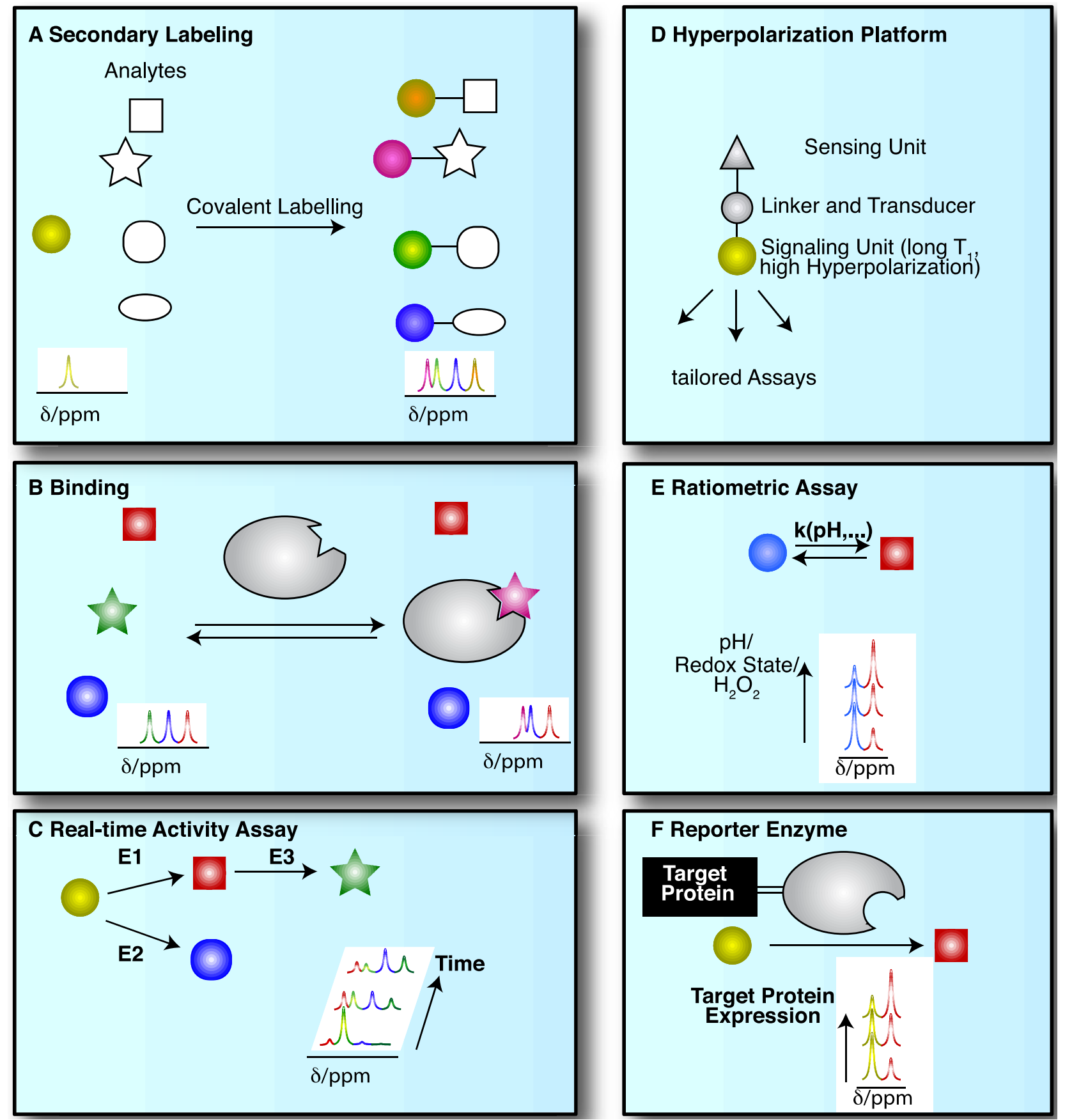

NMR spectroscopy has major applications in drug discovery and in particular in hit and lead generation due to the detection of weak binders and the knowledge-based improvement of initial hits [41]. Hyperpolarization of potential binders or mixtures thereof improves assay sensitivity and reduces material demand. As a consequence, the ${ }^{13} \mathrm{C}-\mathrm{NMR}$ spectroscopic detection of small molecules becomes feasible with good signal-to-noise ratios, thus allowing the observation of binding reactions 
even at natural isotope abundance of ${ }^{13} \mathrm{C}$, in the absence of solvent (water) signal and with a 20 fold larger signal dispersion than ${ }^{1} \mathrm{H}-\mathrm{NMR}$ [42-44]. Figure 3B sketches the use of hyperpolarized probes for the detection of molecular interactions. Binding reactions are also instructive examples for the versatile readout of processes involving hyperpolarized molecular probes beyond chemical shift changes (Figure 3B). Binding to a macromolecular target changes the molecular environment and thus chemical shift of the hyperpolarized probe. In addition, binding to a macromolecular target affects the rotational tumbling of the tracer and leads to a significant shortening of relaxation times, provoking a shortening of the hyperpolarization lifetime by more than an order of magnitude. In consequence, binders can be identified as signals that exhibit changed chemical shift, line widths or strongly accelerated fading of hyperpolarization. This approach likewise has been used to probe hyperpolarized fluorine in drug molecules at several thousand fold improved sensitivity, reducing the material needed to detect and quantify ligand binding in the strong-, intermediate-, and weak-binding regimes [44]. Yet another readout of probe binding is the transfer of hyperpolarization between competitive binders mediated by the binding pocket of the target [42]. The rapid decay of hyperpolarized binders does not require binding partners that are macromolecular, as demonstrated in the magnetic resonance imaging of benzoic acid binding to cyclodextrins by employing the decreased hyperpolarization lifetime upon binding for contrast generation [45].

In addition to probing drug binding, hyperpolarization was also used in monitoring drug metabolism by discontinuous assays. Here, medication levels in blood plasma were monitored for a anticonvulsant (carbamazepine) that was specifically ${ }^{13} \mathrm{C}$ enriched in a position with long hyperpolarization lifetime. Monitoring ${ }^{13} \mathrm{C}$ signals rather than ${ }^{1} \mathrm{H}$ signals of carbamazepine permitted the resolution and identification of the drug in deproteinized blood plasma with accurate and robust quantifications [46]. Additional contrast relative to background signals can be envisioned by monitoring signals with long hyperpolarization lifetime in backgrounds of faster relaxing signals, for instance by following deuterated ${ }^{13} \mathrm{C}$ groups in non-deuterated, rapidly relaxing natural backgrounds.

The most common use of hyperpolarized molecules has been their application in the real-time probing of enzymatic reaction kinetics. In such applications, the chemical conversion of a hyperpolarized organic substrate or metabolite molecule is followed over time, yielding real-time reaction progress curves, also for sequential or parallel reactions (Figure 3C). Once excited to detectable transverse magnetization for detection, hyperpolarization is not recovered. Rather, the transverse component fades with a characteristic transverse relaxation time $T_{2}$ that is shorter than the longitudinal $T_{1}$ time. Hence, progression in binding, transport or chemical reactions is monitored with weak excitation pulses to divide the available hyperpolarized signal for serial, time-resolved readouts [47].

Increased versatility of hyperpolarized probes is recently sought by means of optimized probe design (Figure 3D). Analogous to small fluorescence probe design, hyperpolarized probes have been devised that contain a sensing moiety that is separate from the moiety providing the hyperpolarized NMR signal. Sensing and signaling moieties are then coupled by a transmitter that ensures significant chemical shift changes in the hyperpolarized reporter unit upon events probed by the sensing unit. As the hyperpolarization lifetime is a principal restriction of hyperpolarized NMR probes, the reporter moiety will be selected to provide an atomic site with a hyperpolarization lifetime that is as long as possible. The sensing part of the probe on the other hand is variable and is modified by the analyte of interest. 
Hyperpolarized probes have been used to measure concentrations and conditions such as $\mathrm{pH}, \mathrm{H}_{2} \mathrm{O}_{2}$ and redox state with ratiometric assays, where these conditions affect reaction rates and equilibrium constants of detectable reactions. Hence, the ratio of signals from two reactants has been used both for rapidly established equilibria and in kinetic experiments (of irreversible reactions, at a defined time point) (Figure 3E).

As a final example, enzymatic conversion of hyperpolarized NMR probes has been suggested for a use analogous to the application of optical reporter enzyme/substrate pairs (e.g., luciferase and luciferin) for monitoring the expression of a target gene in cell biology [37,48,49]. In vivo applications of luciferase are limited to observations near the body surface because biological tissues strongly scatter light [37]. Hence, the development of magnetic resonance based reporter protein assays could be advantageous to deep imaging in vivo. In one version employing hyperpolarized probes, the gene of a reporter enzyme is fused to the target gene by genetic engineering (Figure 3F). A hyperpolarized substrate of the reporter enzyme then is used to probe the expression of the chimeric target and reporter gene. The hyperpolarized substrate should be a specific substrate of the reporter enzyme and not be converted by endogenous enzymes [37] (Figure 3F). Readout of exogenous enzymatic activities by hyperpolarized NMR has also been suggested for enzymes that are not intracellularly expressed. Such enzymes were for instance targeted to tissues of interest for the activiation of prodrugs to cytotoxic drugs in tumors [48].

\section{Lifetime of Hyperpolarized NMR Probes}

Due to the limited hyperpolarization lifetime even for small molecules, general considerations in the development of hyperpolarized NMR probes primarily concern the optimization of hyperpolarization levels and lifetimes and the choice of probe and assay conditions favoring a rapid readout. The polarization decays with a longitudinal relaxation rate constant $R_{1}=1 / T_{1}$ that is characteristic for the atomic site at a given temperature, magnetic field and molecular tumbling rate. For spin-1/2 nuclei, relaxation is caused by fluctuating magnetic fields at the sites of the nuclear spins. In the absence of paramagnetic relaxation mechanisms [50], relaxation is usually dominated by a dipolar contribution and a chemical shift anisotropy (CSA) contribution [13].

The dipolar contribution to longitudinal relaxation of a nucleus $\mathrm{X}$ in a molecular probe depends on the nature and distance of nuclear spins as described by the proportionality $R_{\mathrm{d}} \sim \frac{\gamma_{\mathrm{X}}^{2} \gamma_{1 \mathrm{H}}^{2}}{r^{6}}$, where $\gamma$ is the magnetogyric ratio and $r$ the distance from the probe nucleus $\mathrm{X}$ to the dipolar coupled ${ }^{1} \mathrm{H}$ (or other nuclei with large magnetic moment). Hence, hyperpolarized probes will be designed to observe hyperpolarization at a molecular site that is distant from protons, such as quaternary ${ }^{13} \mathrm{C}$ and ${ }^{15} \mathrm{~N}$ atoms [51]. The CSA contribution to longitudinal relaxation is $R_{\mathrm{CSA}} \sim \gamma_{\mathrm{X}}^{2} \Delta \sigma^{2} B_{0}^{2}$, where $B_{0}$ is the magnetic field and $\Delta \sigma$ is the CSA, which is smaller for symmetrical environments. Hence, hyperpolarized probes preferably contain symmetrical environments around the molecular site serving as the reporter or signaling unit. Bearing these considerations in mind, hyperpolarization moieties have been devised that have exponential decay time constants of up to $\sim 15$ minutes (Figure 4 ), where hyperpolarized probing is usually considered feasible on a time scale that is 3-5-fold longer than the exponential decay time. 
Figure 4. Exponential decay time constants for hyperpolarized reporter groups in various designed probes, reaching up to several minutes in symmetrically substituted, non-protonated sites. The reported time constants were derived at $9.4 \mathrm{~T}$ and $25{ }^{\circ} \mathrm{C}$ for ${ }^{89} \mathrm{Y}$-DOTP [28], at $14.1 \mathrm{~T}$ and $37{ }^{\circ} \mathrm{C}$ for permethylated amino acids [51] and at $14.1 \mathrm{~T}$ and $30{ }^{\circ} \mathrm{C}$ for choline- and TMPA-based probes [38].

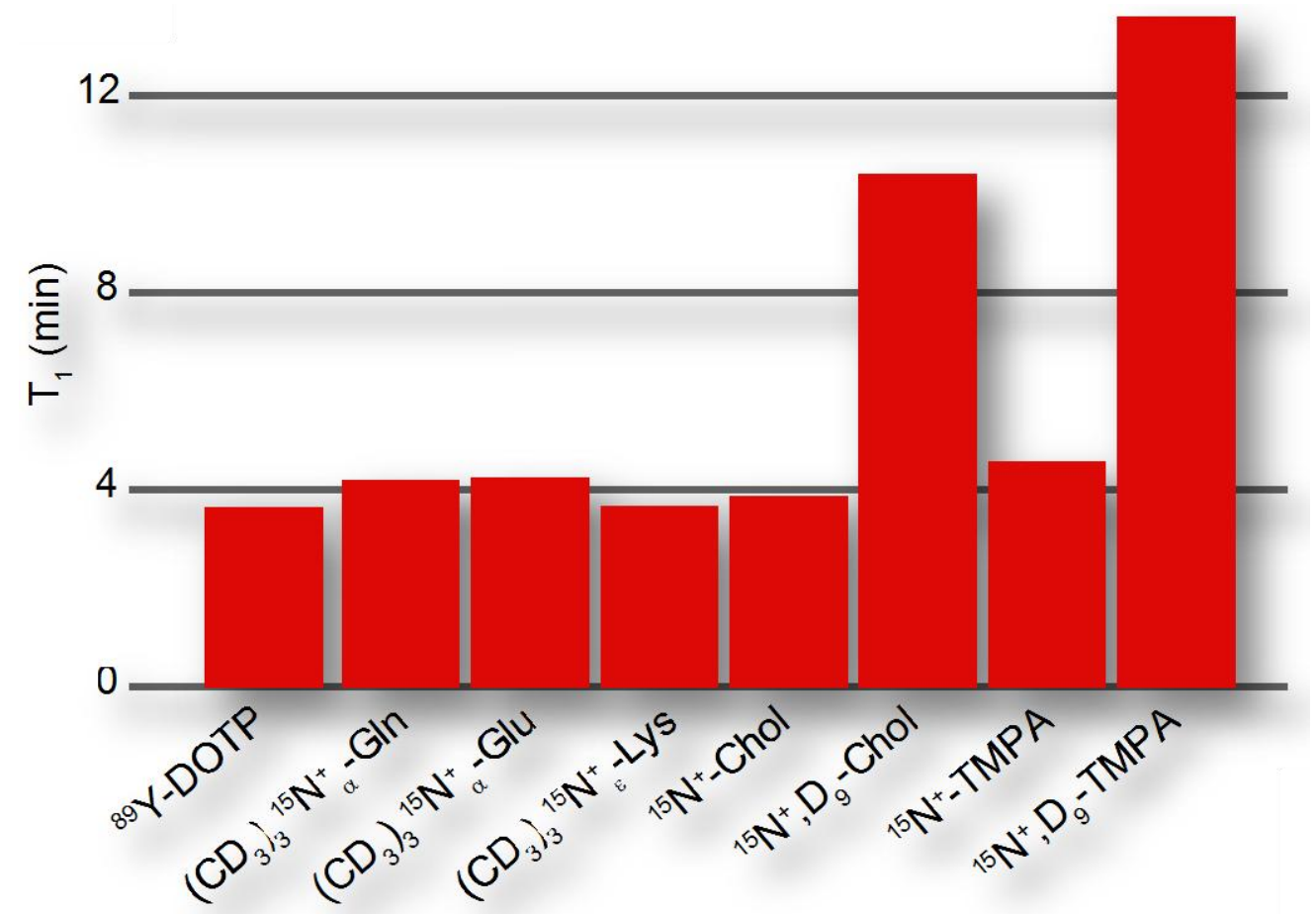

In addition to the direct readout of hyperpolarized signal, magnetization transfer from long $\mathrm{T}_{1}$ nuclei storing hyperpolarized magnetization to other, possibly more informative, molecular sites has been reported in various applications [52-54]. As the hyperpolarization lifetime is the Achilles heel of the method in most applications, approaches to manipulate hyperpolarized nuclear spins with pulse sequences to store hyperpolarization in long lived states are currently under vigorous development $[55,56]$.

\section{Hyperpolarized NMR Probes}

Hyperpolarized NMR probes are advantageously categorized into three classes: (i) Non-endogenous probes that are designed for faster delivery or to contain long lived hyperpolarization units for readout of NMR chemical shift changes upon response of an indicator unit to concentrations or conditions in the analyzed system [28,34,36-38]; (ii) Derivatized endogenous molecules, in particular esters [37,57,58], anhydrides [59] and permethylated amino acids [51], that are modified to improve assay properties such as cellular uptake and hyperpolarization lifetimes; and (iii) Endogenous molecules (bicarbonate, vitamin C, metabolites, nutrients) that are used for minimally invasive assays.

Hyperpolarized probes have been designed to obtain beneficial properties relative to natural substrates. In order to enhance probe response during the hyperpolarization timescale, designed hyperpolarized probes have been devised to provide either longer hyperpolarization lifetimes or faster delivery to the site of action, for instance to the intracellular milieu. Permethylation of amino acids, 
especially with deuterated methyl groups, reduces the proton spin density in the vicinity of amino acid nitrogens and thus decreases relaxation rates of hyperpolarized nitrogen nuclei (Figure 4). When used for perfusion studies, these methylated amino acids do not rapidly enter any metabolic networks [51]. In addition to improving hyperpolarization lifetimes, probes can be derivatized to optimize sample delivery into metabolic networks, for example by esterification of organic acids in order to achieve improved cellular uptake [57,58]. Appropriate balances between hydrophobicity and hydrophilicity should be increasingly considered in optimized probe design particularly for living cell studies, achieving the desired water solubility, membrane permeability and cellular retention of hyperpolarized probes. At the same time, non-natural probes should be biocompatible and bioorthogonal, with the probes exerting no toxic effect in living cells both in their initial or modified forms.

Small natural molecules lend themselves to the direct use as molecular probes if they have non-protonated ${ }^{13} \mathrm{C}$ or ${ }^{15} \mathrm{~N}$ sites. Such sites occur in many metabolites (for instance organic ketones, acids) or can be generated by replacing protons with deuterons, which have much smaller magnetic moments [60,61]. Beyond these considerations, optimization of this class of probes is largely limited to the optimization of hyperpolarization recipes and protocols. As a main benefit, such probes inherently provide biocompatibility if used at near-physiological concentrations. In addition, natural substrates ensure little doubt about the relevance of observed enzyme and pathway activities. The chemical design of small molecule probes, on the other hand, modulates their function relative to the natural substrates [62].

Table 2. Examples of hyperpolarized NMR probing.

\begin{tabular}{llc}
\hline Observable & Probe & References \\
\hline Amino acid concentrations & (i) Designed probes & {$[39]$} \\
\hline Binding & acetic anhydride & {$[42-44]$} \\
\hline Drug metabolism & ${ }^{1} \mathrm{H},{ }^{13} \mathrm{C}$ and ${ }^{19} \mathrm{~F}$ in binders & {$[46]$} \\
\hline $\mathrm{Ca}^{2+}$ concentration & Carbamazepine & {$[38]$} \\
\hline Contrast agent & trimethylphenylammonium ubstituted with & {$[63]$} \\
\hline triacetic acid & LiCl & {$[38]$} \\
\hline Hocl & trimethylphenylammonium substituted with & {$[36]$} \\
\hline Hydrogen peroxide & methyl ester & {$[38,64]$} \\
\hline pH & p-Anisidine & {$[28,34]$} \\
\hline Protein expression & benzoylformic acid trimethylphenylammonium & {$[49]$} \\
\hline & substituted with boronic acid ester & \\
\hline Enzyme activity & ${ }^{89}$ Y-complexes & {$[48]$} \\
\hline Enzyme activity & N-acetyl-L-methionine & {$[57]$} \\
\hline Perfusion & (ii) Derivatized endogenous probes & {$[51]$} \\
\hline Protein expression & 3,5 -Difluorobenzoyl-L-glutamic acid & {$[37]$} \\
\hline
\end{tabular}


Table 2. Cont.

\begin{tabular}{|c|c|c|}
\hline Observable & Probe & References \\
\hline \multicolumn{3}{|c|}{ (iii) Endogenous probes } \\
\hline \multirow{2}{*}{ Cell permeability, lysis } & fumarate metabolism & [65] \\
\hline & pyruvate diffusion & {$[66]$} \\
\hline \multirow{2}{*}{ Drug efficacy } & pyruvate & [67-69] \\
\hline & fumarate & {$[65]$} \\
\hline \multicolumn{3}{|l|}{ Enzyme activities and reaction fluxes } \\
\hline - $\quad$ Ldh & pyruvate, lactate & {$[70,71]$} \\
\hline - $\quad$ Alt & alanine, pyruvate & {$[50]$} \\
\hline - $\quad$ Bcat & ketoisocaproic acid & {$[72]$} \\
\hline - Glutaminase & glutamine & {$[73,74]$} \\
\hline \multirow{4}{*}{$\begin{array}{l}\text { - } \quad \text { Carnitine acetyltransferase, } \\
\text { AcetylCoA synthetase } \\
\text { - } \quad \text { Betaine aldehyde metabolism } \\
\text { - } \quad \text { Pyruvate decarboxylase } \\
\text { - } \quad \text { Pyruvate dehydrogenase }\end{array}$} & acetate & [75] \\
\hline & choline analog & [76] \\
\hline & pyruvate & [77] \\
\hline & pyruvate & {$[78,79]$} \\
\hline \multirow{2}{*}{ Enzyme mechanistic studies } & fructose & [61] \\
\hline & alanine & {$[80]$} \\
\hline Gene expression, gene loss & glucose & {$[61,81]$} \\
\hline \multirow{2}{*}{ Intracellular $\mathrm{pH}$} & acetate & {$[82]$} \\
\hline & pyruvate & [83] \\
\hline $\begin{array}{l}\text { Metabolic strategies in different } \\
\text { genomes }\end{array}$ & glucose & {$[61]$} \\
\hline \multirow{2}{*}{ Oncogene signalling } & pyruvate & {$[84]$} \\
\hline & ketoisocaproic acid & [72] \\
\hline $\begin{array}{l}\text { Pathway activity, bottlenecks } \\
\text { - } \quad \text { Glycolysis } \\
\text { - } \quad \text { Indicator of aerobic glycolysis } \\
\text { - } \quad \text { TCA cycle } \\
\text { - } \quad \text { Fatty acid and ketone body } \\
\quad \text { metabolism } \\
\end{array}$ & $\begin{array}{l}\text { glucose } \\
{\left[1-{ }^{13} \mathrm{C}\right] \text { pyruvate }} \\
{\left[2-{ }^{13} \mathrm{C}\right] \text { pyruvate }} \\
\text { butyrate }\end{array}$ & $\begin{array}{c}{[61,85-87]} \\
{[71,88,89]} \\
{[90]} \\
{[91]}\end{array}$ \\
\hline Redox status & dehydroascorbic acid & {$[92,93]$} \\
\hline Sulfite cytotoxicity & glucose & [94] \\
\hline Tissue $\mathrm{pH}$ & bicarbonate & [95] \\
\hline $\begin{array}{l}\text { Transporter level and activity } \\
\text { - } \quad \text { Glucose transporter } \\
\text { - } \quad \text { Monocarboxylate transporter } \\
\text { - } \quad \text { Urea carrier } \\
\end{array}$ & $\begin{array}{l}\text { glucose } \\
\text { pyruvate } \\
\text { urea }\end{array}$ & $\begin{array}{c}{[86]} \\
{[88,96]} \\
{[97]} \\
\end{array}$ \\
\hline Tumor grading & alanine, pyruvate, lactate & [98] \\
\hline
\end{tabular}

Accordingly, enzyme substrates predominate in this class of molecular probes, even if cellular states and concentrations ( $\mathrm{pH}$, redox state) are measured. Enzymatic substrates provide the advantage of fairly rapid turnover on the time scale of the hyperpolarization lifetime and of amplified signal through catalytic turnover as compared to binding probes [29]. Observed enzymatic and pathway activities report - amongst others - on qualitative and quantitative changes to reaction usage in disease 
biology, altered signaling pathways and cellular modifications in treatment, genetic and genomic changes in cells (including transgenic cells) as well as regulation of reaction usage by nutritional states (Figure 5). Besides chemical turnover in enzyme catalyzed reactions, transport processes have been probed by real-time observation with endogenous substrates to determine estimates of the Michaelis-Menten steady-state kinetic constants of the transporters, specifically the maximal velocities and Michaelis constants of glucose, monocarboxylate or urea transporters [86,88,96,99].

Figure 5. The direct detection of glucose metabolism in Escherichia coli strains shows the accumulation of a lactone intermediate of the pentose phosphate pathway in strain BL21 $(\mathbf{A}, \mathbf{B})$ due to the absence of the lactonase in the BL21 genome, thus affording genomic probing by direct observation of intracellular reaction kinetics; Glc6P = glucose 6-phosphate; PGL = 6-phosphogluconolactone. (C) Accumulation of the lactone occurs in a growth phase dependent manner due to reduced usage of a hyperpolarized glucose probe in biosynthetic pathways as cells approach the stationary phase.

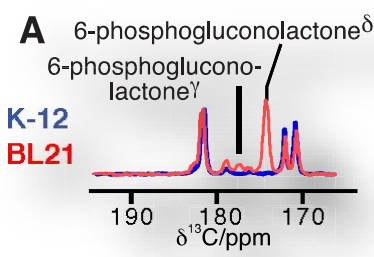

B
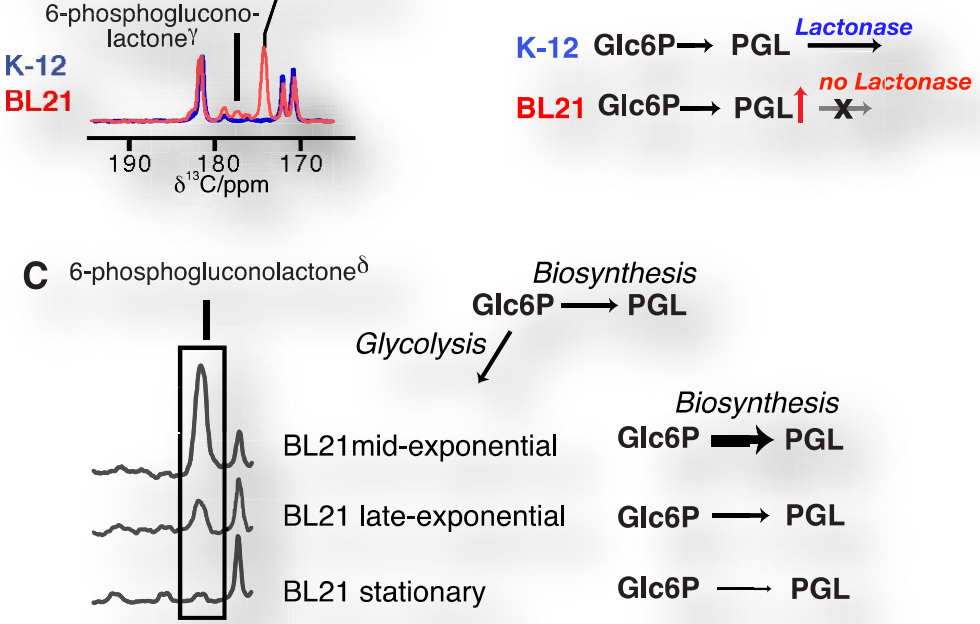

Due to the resolution of individual atomic sites by high-resolution NMR spectroscopic readout, hyperpolarized NMR probes enable the detection of multiple sequential and parallel reactions. Full kinetic reaction profiles of more than ten metabolites, for instance in microbial glycolysis and fermentation reactions, signify the advantage of using high-resolution readouts to the probing of cellular chemistry [61,85]. In doing so, NMR spectroscopic readouts not only identify a plethora of metabolites, but distinguish their precise molecular forms and the reactivity of these forms. Figure $6 \mathrm{~A}$ displays the kinetic profiles of sugar phosphate isomer formation by gluconeogenic reactions using a hyperpolarized $\left[2-{ }^{13} \mathrm{C}\right]$ fructose probe as the glycolytic substrate. Isomer ratios underline the gluconeogenic formation of glucose 6-phosphate and fructose 1,6-bisphosphate from acyclic reaction intermediates under thermodynamic reaction control. Using data from the same in vivo experiment, Figure 6B indicates the slow formation and decay of hydrated dihydroxyacetonephosphate relative to the on-pathway ketone signal upon using hyperpolarized $\left[2-{ }^{13} \mathrm{C}\right]$ fructose as the probe. Both examples in Figure 6 thus probe the in vivo flux of the hyperpolarized signal into off-pathway reactions. On a related note, high spectral resolution also provides the possibility of using several hyperpolarized probes at the same time [100]. 
Figure 6. Time-resolved observation of metabolite isomers upon feeding a hyperpolarized $\left[2-{ }^{13} \mathrm{C}\right]$ fructose probe to a Saccharomyces cerevisiae cell cultures at time 0: (A) Glucose 6-phosphate (Glc6P) and fructose 1,6-bisphosphate $\left(\right.$ Fru1,6 $\left.\mathrm{P}_{2}\right) \mathrm{C}_{5}$ signals arise from gluconeogenic reactions of the glycolytic substrate. Isomer ratios are consistent with the formation of the isomers from acyclic intermediates; (B) real-time observation of dihydroxyaceyone phosphate (DHAP) hydrate formation as an off-pathway glycolytic intermediate (other abbreviations are: GA3P = glyceraldehyde 3-phosphate, Ald = aldolase; $P f k=$ phosphofructokinas $;$ Tpi $=$ triose phosphate isomerase).

A
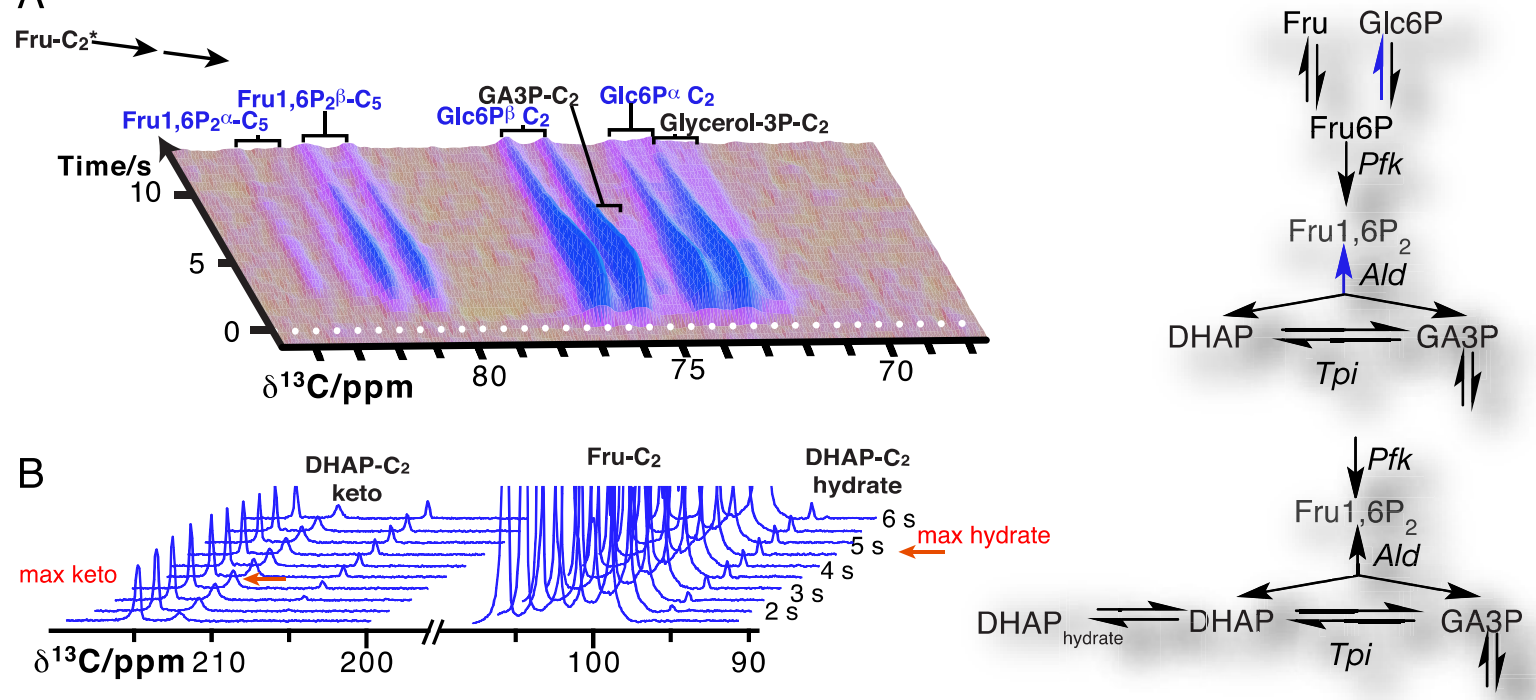

\section{Current Developments and Outlook}

Hyperpolarized NMR probes have rapidly shown their biological, biotechnological and recently also clinical [101] potential. The synergistic co-evolution of probe design and probe formulation as well-glassing preparations [33], in conjunction with technical and methodological developments within hyperpolarization and NMR experimentation leave little doubt of an ongoing improvement of hyperpolarized NMR probe technology and applications within the foreseeable future. An increasing selection of metabolite isotopomers - especially ${ }^{13} \mathrm{C}$ and ${ }^{2} \mathrm{H}$ labeled compounds - will enable more diversified uses of natural (endogenous) hyperpolarized probe molecules for examining biological processes. Diligent choices of probe platforms and the optimization of hyperpolarization conditions will serve to improve probe sensitivity and biocompatibility [102]. Combined optimizations of hyperpolarization lifetime, polarization levels, cellular uptake and retention as well as biocompatibility are yet to be performed for biological assays using hyperpolarized NMR with non-natural probes.

In order to improve assay throughput, approaches employing multiple hyperpolarization chambers [103-105] have been used for multiplexed probe generation. In addition, polarization of ${ }^{1} \mathrm{H}$ and subsequent transfer to nuclei with low magnetogyric ratio [106] is a means towards faster hyperpolarization with the DNP method. In addition to using several chambers for probe generation, the use of several chambers for parallel detection in assays, e.g., in multi-chamber bioreactors, will improve assay throughput [107]. The development and use of bioreactors for sustained cell cultures will support assay reproducibility in this context [88,89]. 
Various NMR methods have been described that provide increased temporal and spatial resolution as well as information content in hyperpolarized probe detection [108-114]. The approaches include modified detection schemes to generate multidimensional spectra from rapid single-scan NMR experiments [54,115-117] or the indirect, amplified detection of signals by saturation transfer methods [86,118]. As mentioned above, a major undertaking is to store hyperpolarization in slowly fading nuclear spin states in order to enhance the utility of hyperpolarized NMR probes in the detection of slower reactions or more pathway steps. Additionally, the assay time window has been extended towards the short end of the time scale by establishing rapid delivery of hyperpolarized substrates into the NMR detection system [119,120]. Resultant time-resolved reaction progression curves over an expanding time scale predictably will increasingly need to be analysed with realistic mathematical models in order to extract quantitative kinetic data [70,71,99,121]. Besides such methodological and technological improvements, ease of use and affordability clearly constitute a major point of concern, especially if hyperpolarized NMR probes are meant to experience routine use in cell biological and clinical assays. While there is room for improvement, hyperpolarized NMR probes already offer a plethora of unique benefits, such as: molecular information and spectral resolution; low background polarization and interference; simultaneous analyte detection; minimal invasiveness especially when using endogenous molecules as probes; the use of non-ionizing electromagnetic radiation with virtually unlimited permeation into tissues and other samples.

Overall, NMR spectroscopy allows minimally invasive observation of complex processes and systems. The development of hyperpolarized probes enables the direct quantitative understanding of such processes and systems in selective assay developed directly for biofluid and cellular settings. In consequence, analytical methods using hyperpolarized NMR help avoid overly optimistic conclusions regarding biological utility and specificity, which can occur with less direct methods that use few selected targets under test tube conditions. Therefore, the use of hyperpolarized probes on complex systems, in conjunction with atomic-resolution NMR detection of probe transport and conversion, has great potential in enhancing our understanding of biological systems.

\section{Acknowledgments}

We gratefully acknowledge Ole Hindsgaul for continued support of DNP NMR projects and Sophie Beeren for critically reading the manuscript and for helpful discussions.

\section{Conflicts of Interest}

The authors declare no conflict of interest.

\section{References}

1. Palmer, A.E.; Qin, Y.; Park, J.G.; McCombs, J.E. Design and application of genetically encoded biosensors. Trends Biotechnol. 2011, 29, 144-152.

2. Svatos, A. Single-cell metabolomics comes of age: New developments in mass spectrometry profiling and imaging. Anal. Chem. 2011, 83, 5037-5044. 
3. Chan, J.; Dodani, S.C.; Chang, C.J. Reaction-based small-molecule fluorescent probes for chemoselective bioimaging. Nat. Chem. 2012, 4, 973-984.

4. Holman, H.Y.; Bechtel, H.A.; Hao, Z.; Martin, M.C. Synchrotron IR spectromicroscopy: Chemistry of living cells. Anal. Chem. 2010, 82, 8757-8765.

5. Evans, C.L.; Xie, X.S. Coherent anti-stokes raman scattering microscopy: Chemical imaging for biology and medicine. Annu. Rev. Anal. Chem. 2008, 1, 883-909.

6. Schroeder, M.A.; Clarke, K.; Neubauer, S.; Tyler, D.J. Hyperpolarized magnetic resonance: A novel technique for the in vivo assessment of cardiovascular disease. Circulation 2011, 124, 1580-1594.

7. Gallagher, F.A.; Kettunen, M.I.; Day, S.E.; Hu, D.-E.; Karlsson, M.; Gisselsson, A.; Lerche, M.H.; Brindle, K.M. Detection of tumor glutamate metabolism in vivo using ${ }^{13} \mathrm{C}$ magnetic resonance spectroscopy and hyperpolarized $\left[1-{ }^{13} \mathrm{C}\right]$ glutamate. Magn. Reson. Med. 2011, 66, 18-23.

8. Kurhanewicz, J.; Vigneron, D.B.; Brindle, K.; Chekmenev, E.Y.; Comment, A.; Cunningham, C.H.; Deberardinis, R.J.; Green, G.G.; Leach, M.O.; Rajan, S.S.; et al. Analysis of cancer metabolism by imaging hyperpolarized nuclei: Prospects for translation to clinical research. Neoplasia 2011, 13, 81-97.

9. Terreno, E.; Castelli, D.D.; Viale, A.; Aime, S. Challenges for molecular magnetic resonance imaging. Chem. Rev. 2010, 110, 3019-3042.

10. Derome, A.E. Modern NMR Techniques for Chemistry Research, 1st ed.; Pergamon Press: Oxford, UK, 1987.

11. De Graaf, R.A. In vivo NMR Spectroscopy : Principles and Techniques, 2nd ed.; Wiley: Chichester, UK; Hoboken, NJ, USA, 2007.

12. Cavanagh, J. Protein NMR Spectroscopy : Principles and Practice, 2nd ed.; Academic Press: Amsterdam, The Netherland; Boston, MA, USA, 2007.

13. Levitt, M.H. Spin Dynamics : Basics of Nuclear Magnetic Resonance, 2nd ed.; Wiley: Chichester, England, UK; Hoboken, NJ, USA, 2008.

14. Bowers, C.R.; Weitekamp, D.P. Transformation of symmetrization order to nuclear-spin magnetization by chemical reaction and nuclear magnetic resonance. Phys. Rev. Lett. 1986, 57, 2645-2648.

15. Middleton, H.; Black, R.D.; Saam, B.; Cates, G.D.; Cofer, G.P.; Guenther, R.; Happer, W.; Hedlund, L.W.; Johnson, G.A.; Juvan, K.; et al. MR imaging with hyperpolarized ${ }^{3} \mathrm{He}$ gas. Magn. Reson. Med. 1995, 33, 271-275.

16. Spence, M.M.; Rubin, S.M.; Dimitrov, I.E.; Ruiz, E.J.; Wemmer, D.E.; Pines, A.; Yao, S.Q.; Tian, F.; Schultz, P.G. Functionalized xenon as a biosensor. Proc. Natl. Acad. Sci. USA 2001, 98 , 10654-10657.

17. Haupt, J. A new effect of dynamic polarization in a solid obtained by rapid change of temperature. Phys. Lett. A 1972, 38, 389-390.

18. Günther, U.L. Dynamic nuclear hyperpolarization in liquids. Top. Curr. Chem. 2013, 335, 23-69.

19. Carver, T.R.; Slichter, C.P. Polarization of nuclear spins in metals. Phys. Rev. 1953, 92, $212-213$. 
20. Abragam, A.; Goldman, M. Principles of dynamic nuclear polarisation. Rep. Prog. Phys. 1978, $41,395$.

21. Abraham, M.; McCausland, M.A.H.; Robinson, F.N.H. Dynamic nuclear polarization. Phys. Rev. Lett. 1959, 2, 449-451.

22. Carver, T.R.; Slichter, C.P. Experimental verification of the overhauser nuclear polarization effect. Phys. Rev. 1956, 102, 975-980.

23. Abragam, A.; Goldman, M. Nuclear Magnetism: Order and Disorder; Oxford University Press: New York, NY, USA, 1982.

24. Comment, A.; van den Brandt, B.; Uffmann, K.; Kurdzesau, F.; Jannin, S.; Konter, J.A.; Hautle, P.; Wenckebach, W.T.; Grütter, R.; van der Klink, J.J. Design and performance of a DNP prepolarizer coupled to a rodent MRI scanner. Concepts Magn. Reson. B 2007, 31B, 255-269.

25. Ardenkjær-Larsen, J.H.; Fridlund, B.; Gram, A.; Hansson, G.; Hansson, L.; Lerche, M.H.; Servin, R.; Thaning, M.; Golman, K. Increase in signal-to-noise ratio of >10,000 times in liquid-state NMR. Proc. Natl. Acad. Sci. USA 2003, 100, 10158-10163.

26. Lumata, L.; Merritt, M.E.; Hashami, Z.; Ratnakar, S.J.; Kovacs, Z. Production and NMR characterization of hyperpolarized ${ }^{107,109} \mathrm{Ag}$ complexes. Angew. Chem. Int. Ed. Engl. 2012, 51, 525-527.

27. Dementyev, A.E.; Cory, D.G.; Ramanathan, C. Dynamic nuclear polarization in silicon microparticles. Phys. Rev. Lett. 2008, 100, 127601.

28. Jindal, A.K.; Merritt, M.E.; Suh, E.H.; Malloy, C.R.; Sherry, A.D.; Kovacs, Z. Hyperpolarized ${ }^{89} \mathrm{Y}$ complexes as $\mathrm{pH}$ sensitive NMR probes. J. Am. Chem. Soc. 2010, 132, 1784-1785.

29. Schröder, L. Xenon for NMR biosensing-Inert but alert. Phys. Med. 2013, 29, 3-16.

30. Harris, R.K.; Becker, E.D.; Cabral de Menezes, S.M.; Goodfellow, R.; Granger, P. NMR nomenclature: Nuclear spin properties and conventions for chemical shifts. Iupac recommendations 2001. Solid State Nucl. Magn. Reson. 2002, 22, 458-483.

31. Sakakibara, D.; Sasaki, A.; Ikeya, T.; Hamatsu, J.; Hanashima, T.; Mishima, M.; Yoshimasu, M.; Hayashi, N.; Mikawa, T.; Wälchli, M.; et al. Protein structure determination in living cells by in-cell NMR spectroscopy. Nature 2009, 458, 102-105.

32. Serber, Z.; Dotsch, V. In-cell NMR spectroscopy. Biochemistry 2001, 40, 14317-14323.

33. Karlsson, M.; Jensen, P.; Duus, J.Ø.; Meier, S.; Lerche, M. Development of dissolution DNP-MR substrates for metabolic research. Appl. Magn. Reson. 2012, 43, 223-236.

34. Lumata, L.; Jindal, A.K.; Merritt, M.E.; Malloy, C.R.; Sherry, A.D.; Kovacs, Z. DNP by thermal mixing under optimized conditions yields $>60,000$-fold enhancement of ${ }^{89}$ Y NMR signal. $J$. Am. Chem. Soc. 2011, 133, 8673-8680.

35. Bowen, S.; Ardenkjær-Larsen, J.H. Formulation and utilization of choline based samples for dissolution dynamic nuclear polarization. J. Magn. Reson. 2013, 236, 26-30.

36. Doura, T.; Hata, R.; Nonaka, H.; Ichikawa, K.; Sando, S. Design of a ${ }^{13} \mathrm{C}$ magnetic resonance probe using a deuterated methoxy group as a long-lived hyperpolarization unit. Angew. Chem. Int. Ed. Engl. 2012, 51, 10114-10117. 
37. Nishihara, T.; Nonaka, H.; Naganuma, T.; Ichikawa, K.; Sando, S. Mouse lactate dehydrogenase X: A promising magnetic resonance reporter protein using hyperpolarized pyruvic acid derivative $\mathrm{Y}$. Chem. Sci. 2012, 3, 800-806.

38. Nonaka, H.; Hata, R.; Doura, T.; Nishihara, T.; Kumagai, K.; Akakabe, M.; Tsuda, M.; Ichikawa, K.; Sando, S. A platform for designing hyperpolarized magnetic resonance chemical probes. Nat. Commun. 2013, 4, doi:10.1038/ncomms3411.

39. Wilson, D.M.; Hurd, R.E.; Keshari, K.; Van Criekinge, M.; Chen, A.P.; Nelson, S.J.; Vigneron, D.B.; Kurhanewicz, J. Generation of hyperpolarized substrates by secondary labeling with $\left[1,1-{ }^{13} \mathrm{C}\right]$ acetic anhydride. Proc. Natl. Acad. Sci. USA 2009, 106, 5503-5507.

40. Shanaiah, N.; Desilva, M.A.; Nagana Gowda, G.A.; Raftery, M.A.; Hainline, B.E.; Raftery, D. Class selection of amino acid metabolites in body fluids using chemical derivatization and their enhanced ${ }^{13}$ C NMR. Proc. Natl. Acad. Sci. USA 2007, 104, 11540-11544.

41. Pellecchia, M.; Bertini, I.; Cowburn, D.; Dalvit, C.; Giralt, E.; Jahnke, W.; James, T.L.; Homans, S.W.; Kessler, H.; Luchinat, C.; et al. Perspectives on NMR in drug discovery: A technique comes of age. Nat. Rev. Drug Discov. 2008, 7, 738-745.

42. Lee, Y.; Zeng, H.; Mazur, A.; Wegstroth, M.; Carlomagno, T.; Reese, M.; Lee, D.; Becker, S.; Griesinger, C.; Hilty, C. Hyperpolarized binding pocket nuclear overhauser effect for determination of competitive ligand binding. Angew. Chem. Int. Ed. Engl. 2012, 51, 5179-5182.

43. Lerche, M.H.; Meier, S.; Jensen, P.R.; Baumann, H.; Petersen, B.O.; Karlsson, M.; Duus, J.Ø.; Ardenkjær-Larsen, J.H. Study of molecular interactions with ${ }^{13} \mathrm{C}$ DNP-NMR. J. Magn. Reson. 2010, 203, 52-56.

44. Lee, Y.; Zeng, H.; Rüdisser, S.; Gossert, A.D.; Hilty, C. Nuclear magnetic resonance of hyperpolarized fluorine for characterization of protein-ligand interactions. J. Am. Chem. Soc. 2012, 134, 17448-17451.

45. Keshari, K.R.; Kurhanewicz, J.; Macdonald, J.M.; Wilson, D.M. Generating contrast in hyperpolarized ${ }^{13} \mathrm{C}$ MRI using ligand-receptor interactions. Analyst 2012, 137, 3427-3429.

46. Lerche, M.H.; Meier, S.; Jensen, P.R.; Hustvedt, S.O.; Karlsson, M.; Duus, J.Ø.; Ardenkjær-Larsen, J.H. Quantitative dynamic nuclear polarization-NMR on blood plasma for assays of drug metabolism. NMR Biomed. 2011, 24, 96-103.

47. Golman, K.; Zandt, R.I.; Lerche, M.; Pehrson, R.; Ardenkjær-Larsen, J.H. Metabolic imaging by hyperpolarized ${ }^{13} \mathrm{C}$ magnetic resonance imaging for in vivo tumor diagnosis. Cancer Res. 2006, 66, 10855-10860.

48. Jamin, Y.; Gabellieri, C.; Smyth, L.; Reynolds, S.; Robinson, S.P.; Springer, C.J.; Leach, M.O.; Payne, G.S.; Eykyn, T.R. Hyperpolarized ${ }^{13} \mathrm{C}$ magnetic resonance detection of carboxypeptidase G2 activity. Magn. Reson. Med. 2009, 62, 1300-1304.

49. Chen, A.P.; Hurd, R.E.; Gu, Y.P.; Wilson, D.M.; Cunningham, C.H. ${ }^{13} \mathrm{C}$ MR reporter probe system using dynamic nuclear polarization. NMR Biomed. 2011, 24, 514-520.

50. Jensen, P.R.; Karlsson, M.; Meier, S.; Duus, J.Ø.; Lerche, M.H. Hyperpolarized amino acids for in vivo assays of transaminase activity. Chemistry 2009, 15, 10010-10012.

51. Chiavazza, E.; Viale, A.; Karlsson, M.; Aime, S. ${ }^{15} \mathrm{~N}$-permethylated amino acids as efficient probes for MRI-DNP applications. Contrast Media Mol. Imaging 2013, 8, 417-421. 
52. Barb, A.W.; Hekmatyar, S.K.; Glushka, J.N.; Prestegard, J.H. Exchange facilitated indirect detection of hyperpolarized ${ }^{15} \mathrm{ND}_{2}$-amido-glutamine. J. Magn. Reson. 2011, 212, 304-310.

53. Sarkar, R.; Comment, A.; Vasos, P.R.; Jannin, S.; Grütter, R.; Bodenhausen, G.; Hall, H.; Kirik, D.; Denisov, V.P. Proton NMR of ${ }^{15} \mathrm{~N}$-choline metabolites enhanced by dynamic nuclear polarization. J. Am. Chem. Soc. 2009, 131, 16014-16015.

54. Ludwig, C.; Marin-Montesinos, I.; Saunders, M.G.; Emwas, A.H.; Pikramenou, Z.; Hammond, S.P.; Günther, U.L. Application of ex situ dynamic nuclear polarization in studying small molecules. Phys. Chem. Chem. Phys. 2010, 12, 5868-5871.

55. Theis, T.; Feng, Y.; Wu, T.-L.; Warren, W.S. Spin lock composite and shaped pulses for efficient and robust pumping of dark states in magnetic resonance. 2013, arXiv:1308.5666. arXiv.org e-Print archive. Available online: http://arxiv.org/ftp/arxiv/papers/1308/1308.5666.pdf (accessed on 16 Juanuary 2014).

56. Levitt, M.H. Singlet nuclear magnetic resonance. Annu. Rev. Phys. Chem. 2012, 63, 89-105.

57. Hurd, R.E.; Yen, Y.F.; Mayer, D.; Chen, A.; Wilson, D.; Kohler, S.; Bok, R.; Vigneron, D.; Kurhanewicz, J.; Tropp, J.; et al. Metabolic imaging in the anesthetized rat brain using hyperpolarized $\left[1-{ }^{13} \mathrm{C}\right]$ pyruvate and $\left[1-{ }^{13} \mathrm{C}\right]$ ethyl pyruvate. Magn. Reson. Med. 2010, 63, 1137-1143.

58. Zacharias, N.M.; Chan, H.R.; Sailasuta, N.; Ross, B.D.; Bhattacharya, P. Real-time molecular imaging of tricarboxylic acid cycle metabolism in vivo by hyperpolarized $1-{ }^{13} \mathrm{C}$ diethyl succinate. J. Am. Chem. Soc. 2012, 134, 934-943.

59. Colombo Serra, S.; Karlsson, M.; Giovenzana, G.B.; Cavallotti, C.; Tedoldi, F.; Aime, S. Hyperpolarized ${ }^{13}$ C-labelled anhydrides as DNP precursors of metabolic MRI agents. Contrast Media Mol. Imaging 2012, 7, 469-477.

60. Allouche-Arnon, H.; Lerche, M.H.; Karlsson, M.; Lenkinski, R.E.; Katz-Brull, R. Deuteration of a molecular probe for DNP hyperpolarization-A new approach and validation for choline chloride. Contrast Media Mol. Imaging 2011, 6, 499-506.

61. Meier, S.; Jensen, P.R.; Duus, J.Ø. Real-time detection of central carbon metabolism in living escherichia coli and its response to perturbations. FEBS Lett. 2011, 585, 3133-3138.

62. Xie, X.S.; Yu, J.; Yang, W.Y. Living cells as test tubes. Science 2006, 312, 228-230.

63. van Heeswijk, R.B.; Uffmann, K.; Comment, A.; Kurdzesau, F.; Perazzolo, C.; Cudalbu, C.; Jannin, S.; Konter, J.A.; Hautle, P.; van den Brandt, B.; et al. Hyperpolarized lithium-6 as a sensor of nanomolar contrast agents. Magn. Reson. Med. 2009, 61, 1489-1493.

64. Lippert, A.R.; Keshari, K.R.; Kurhanewicz, J.; Chang, C.J. A hydrogen peroxide-responsive hyperpolarized ${ }^{13} \mathrm{C}$ MRI contrast agent. J. Am. Chem. Soc. 2011, 133, 3776-3779.

65. Gallagher, F.A.; Kettunen, M.I.; Hu, D.E.; Jensen, P.R.; Zandt, R.I.; Karlsson, M.; Gisselsson, A.; Nelson, S.K.; Witney, T.H.; Bohndiek, S.E.; et al. Production of hyperpolarized $\left[1,4-{ }^{13} \mathrm{C}_{2}\right]$ malate from $\left[1,4-{ }^{13} \mathrm{C}_{2}\right]$ fumarate is a marker of cell necrosis and treatment response in tumors. Proc. Natl. Acad. Sci. USA 2009, 106, 19801-19806.

66. Schilling, F.; Duwel, S.; Kollisch, U.; Durst, M.; Schulte, R.F.; Glaser, S.J.; Haase, A.; Otto, A.M.; Menzel, M.I. Diffusion of hyperpolarized ${ }^{13} \mathrm{C}$-metabolites in tumor cell spheroids using real-time NMR spectroscopy. NMR Biomed. 2013, 26, 557-568. 
67. Day, S.E.; Kettunen, M.I.; Gallagher, F.A.; Hu, D.E.; Lerche, M.; Wolber, J.; Golman, K.; Ardenkjær-Larsen, J.H.; Brindle, K.M. Detecting tumor response to treatment using hyperpolarized ${ }^{13} \mathrm{C}$ magnetic resonance imaging and spectroscopy. Nat. Med. 2007, 13, 1382-1387.

68. Lodi, A.; Woods, S.M.; Ronen, S.M. Treatment with the MEK inhibitor U0126 induces decreased hyperpolarized pyruvate to lactate conversion in breast, but not prostate, cancer cells. NMR Biomed. 2013, 26, 299-306.

69. Venkatesh, H.S.; Chaumeil, M.M.; Ward, C.S.; Haas-Kogan, D.A.; James, C.D.; Ronen, S.M. Reduced phosphocholine and hyperpolarized lactate provide magnetic resonance biomarkers of PI3K/Akt/mTOR inhibition in glioblastoma. Neuro Oncol. 2012, 14, 315-325.

70. Harrison, C.; Yang, C.; Jindal, A.; DeBerardinis, R.J.; Hooshyar, M.A.; Merritt, M.; Sherry, A.D.; Malloy, C.R. Comparison of kinetic models for analysis of pyruvate-to-lactate exchange by hyperpolarized ${ }^{13} \mathrm{C}$ NMR. NMR Biomed. 2012, 25, 1286-1294.

71. Witney, T.H.; Kettunen, M.I.; Brindle, K.M. Kinetic modeling of hyperpolarized ${ }^{13} \mathrm{C}$ label exchange between pyruvate and lactate in tumor cells. J. Biol. Chem. 2011, 286, 24572-24580.

72. Karlsson, M.; Jensen, P.R.; in't Zandt, R.; Gisselsson, A.; Hansson, G.; Duus, J.Ø.; Meier, S.; Lerche, M.H. Imaging of branched chain amino acid metabolism in tumors with hyperpolarized ${ }^{13}$ C ketoisocaproate. Int. J. Cancer 2010, 127, 729-736.

73. Gallagher, F.A.; Kettunen, M.I.; Day, S.E.; Lerche, M.; Brindle, K.M. ${ }^{13}$ C MR spectroscopy measurements of glutaminase activity in human hepatocellular carcinoma cells using hyperpolarized ${ }^{13} \mathrm{C}$-labeled glutamine. Magn. Reson. Med. 2008, 60, 253-257.

74. Cabella, C.; Karlsson, M.; Canape, C.; Catanzaro, G.; Colombo Serra, S.; Miragoli, L.; Poggi, L.; Uggeri, F.; Venturi, L.; Jensen, P.R.; et al. In vivo and in vitro liver cancer metabolism observed with hyperpolarized $\left[5-{ }^{13}\right.$ C]glutamine. J. Magn. Reson. 2013, 232, 45-52.

75. Jensen, P.R.; Peitersen, T.; Karlsson, M.; in't Zandt, R.; Gisselsson, A.; Hansson, G.; Meier, S.; Lerche, M.H. Tissue-specific short chain fatty acid metabolism and slow metabolic recovery after ischemia from hyperpolarized NMR in vivo. J. Biol. Chem. 2009, 284, 36077-36082.

76. Allouche-Arnon, H.; Gamliel, A.; Sosna, J.; Gomori, J.M.; Katz-Brull, R. In vitro visualization of betaine aldehyde synthesis and oxidation using hyperpolarized magnetic resonance spectroscopy. Chem. Commun. 2013, 49, 7076-7078.

77. Merritt, M.E.; Harrison, C.; Sherry, A.D.; Malloy, C.R.; Burgess, S.C. Flux through hepatic pyruvate carboxylase and phosphoenolpyruvate carboxykinase detected by hyperpolarized ${ }^{13} \mathrm{C}$ magnetic resonance. Proc. Natl. Acad. Sci. USA 2011, 108, 19084-19089.

78. Merritt, M.E.; Harrison, C.; Storey, C.; Jeffrey, F.M.; Sherry, A.D.; Malloy, C.R. Hyperpolarized ${ }^{13} \mathrm{C}$ allows a direct measure of flux through a single enzyme-catalyzed step by NMR. Proc. Natl. Acad. Sci. USA 2007, 104, 19773-19777.

79. Schroeder, M.A.; Cochlin, L.E.; Heather, L.C.; Clarke, K.; Radda, G.K.; Tyler, D.J. In vivo assessment of pyruvate dehydrogenase flux in the heart using hyperpolarized carbon-13 magnetic resonance. Proc. Natl. Acad. Sci. USA 2008, 105, 12051-12056.

80. Barb, A.W.; Hekmatyar, S.K.; Glushka, J.N.; Prestegard, J.H. Probing alanine transaminase catalysis with hyperpolarized ${ }^{13} \mathrm{CD}_{3}$-pyruvate. J. Magn. Reson. 2013, 228, 59-65.

81. Meier, S.; Jensen, P.R.; Duus, J.Ø. Direct observation of metabolic differences in living escherichia coli strains K-12 and BL21. ChemBioChem 2012, 13, 308-310. 
82. Jensen, P.R.; Karlsson, M.; Lerche, M.H.; Meier, S. Real-time DNP NMR observations of acetic acid uptake, intracellular acidification, and of consequences for glycolysis and alcoholic fermentation in yeast. Chemistry 2013, 19, 13288-13293.

83. Schroeder, M.A.; Swietach, P.; Atherton, H.J.; Gallagher, F.A.; Lee, P.; Radda, G.K.; Clarke, K.; Tyler, D.J. Measuring intracellular $\mathrm{pH}$ in the heart using hyperpolarized carbon dioxide and bicarbonate: $\mathrm{A}^{13} \mathrm{C}$ and ${ }^{31} \mathrm{P}$ magnetic resonance spectroscopy study. Cardiovasc. Res. 2010, 86, 82-91.

84. Hu, S.; Balakrishnan, A.; Bok, R.A.; Anderton, B.; Larson, P.E.; Nelson, S.J.; Kurhanewicz, J.; Vigneron, D.B.; Goga, A. ${ }^{13} \mathrm{C}$-pyruvate imaging reveals alterations in glycolysis that precede c-myc-induced tumor formation and regression. Cell. Metab. 2011, 14, 131-142.

85. Meier, S.; Karlsson, M.; Jensen, P.R.; Lerche, M.H.; Duus, J.Ø. Metabolic pathway visualization in living yeast by DNP-NMR. Mol. Biosyst. 2011, 7, 2834-2836.

86. Harris, T.; Degani, H.; Frydman, L. Hyperpolarized ${ }^{13} \mathrm{C}$ NMR studies of glucose metabolism in living breast cancer cell cultures. NMR Biomed. 2013, 26, 1831-1843.

87. Rodrigues, T.B.; Serrao, E.M.; Kennedy, B.W.; Hu, D.E.; Kettunen, M.I.; Brindle, K.M. Magnetic resonance imaging of tumor glycolysis using hyperpolarized ${ }^{13} \mathrm{C}$ labeled glucose. Nat. Med. 2013, doi:10.1038/nm.3416.

88. Harris, T.; Eliyahu, G.; Frydman, L.; Degani, H. Kinetics of hyperpolarized ${ }^{13} \mathrm{C}_{1}$-pyruvate transport and metabolism in living human breast cancer cells. Proc. Natl. Acad. Sci. USA 2009, 106, 18131-18136.

89. Keshari, K.R.; Kurhanewicz, J.; Jeffries, R.E.; Wilson, D.M.; Dewar, B.J.; Van Criekinge, M.; Zierhut, M.; Vigneron, D.B.; Macdonald, J.M. Hyperpolarized ${ }^{13} \mathrm{C}$ spectroscopy and an NMR-compatible bioreactor system for the investigation of real-time cellular metabolism. Magn. Reson. Med. 2010, 63, 322-329.

90. Schroeder, M.A.; Atherton, H.J.; Ball, D.R.; Cole, M.A.; Heather, L.C.; Griffin, J.L.; Clarke, K.; Radda, G.K.; Tyler, D.J. Real-time assessment of krebs cycle metabolism using hyperpolarized ${ }^{13} \mathrm{C}$ magnetic resonance spectroscopy. FASEB J. 2009, 23, 2529-2538.

91. Ball, D.R.; Rowlands, B.; Dodd, M.S.; Le Page, L.; Ball, V.; Carr, C.A.; Clarke, K.; Tyler, D.J. Hyperpolarized butyrate: A metabolic probe of short chain fatty acid metabolism in the heart. Magn. Reson. Med. 2013, doi:10.1002/mrm.24849.

92. Bohndiek, S.E.; Kettunen, M.I.; Hu, D.E.; Kennedy, B.W.; Boren, J.; Gallagher, F.A.; Brindle, K.M. Hyperpolarized $\left[1-{ }^{13} \mathrm{C}\right]$-ascorbic and dehydroascorbic acid: Vitamin $\mathrm{C}$ as a probe for imaging redox status in vivo. J. Am. Chem. Soc. 2011, 133, 11795-11801.

93. Keshari, K.R.; Kurhanewicz, J.; Bok, R.; Larson, P.E.; Vigneron, D.B.; Wilson, D.M. Hyperpolarized ${ }^{13} \mathrm{C}$ dehydroascorbate as an endogenous redox sensor for in vivo metabolic imaging. Proc. Natl. Acad. Sci. USA 2011, 108, 18606-18611.

94. Meier, S.; Solodovnikova, N.; Jensen, P.R.; Wendland, J. Sulfite action in glycolytic inhibition: In vivo real-time observation by hyperpolarized ${ }^{13} \mathrm{C}$ NMR spectroscopy. ChemBioChem 2012, $13,2265-2269$.

95. Gallagher, F.A.; Kettunen, M.I.; Day, S.E.; Hu, D.E.; Ardenkjær-Larsen, J.H.; in't Zandt, R.; Jensen, P.R.; Karlsson, M.; Golman, K.; Lerche, M.H.; et al. Magnetic resonance imaging of pH in vivo using hyperpolarized ${ }^{13} \mathrm{C}$-labelled bicarbonate. Nature 2008, 453, 940-943. 
96. Keshari, K.R.; Sriram, R.; Koelsch, B.L.; Van Criekinge, M.; Wilson, D.M.; Kurhanewicz, J.; Wang, Z.J. Hyperpolarized ${ }^{13} \mathrm{C}$-pyruvate magnetic resonance reveals rapid lactate export in metastatic renal cell carcinomas. Cancer Res. 2013, 73, 529-538.

97. Pages, G.; Puckeridge, M.; Liangfeng, G.; Tan, Y.L.; Jacob, C.; Garland, M.; Kuchel, P.W. Transmembrane exchange of hyperpolarized ${ }^{13} \mathrm{C}$-urea in human erythrocytes: Subminute timescale kinetic analysis. Biophys. J. 2013, 105, 1956-1966.

98. Albers, M.J.; Bok, R.; Chen, A.P.; Cunningham, C.H.; Zierhut, M.L.; Zhang, V.Y.; Kohler, S.J.; Tropp, J.; Hurd, R.E.; Yen, Y.F.; et al. Hyperpolarized ${ }^{13} \mathrm{C}$ lactate, pyruvate, and alanine: Noninvasive biomarkers for prostate cancer detection and grading. Cancer Res. 2008, 68, 8607-8615.

99. Pagès, G.; Kuchel, P.W. Mathematical modeling and data analysis of NMR experiments using hyperpolarized ${ }^{13} \mathrm{C}$ metabolites. Magn. Reson. Insights 2013, 6, 13-21.

100. Wilson, D.M.; Keshari, K.R.; Larson, P.E.; Chen, A.P.; Hu, S.; Van Criekinge, M.; Bok, R.; Nelson, S.J.; Macdonald, J.M.; Vigneron, D.B.; et al. Multi-compound polarization by DNP allows simultaneous assessment of multiple enzymatic activities in vivo. J. Magn. Reson. 2010, 205, 141-147.

101. Nelson, S.J.; Kurhanewicz, J.; Vigneron, D.B.; Larson, P.E.; Harzstark, A.L.; Ferrone, M.; van Criekinge, M.; Chang, J.W.; Bok, R.; Park, I.; et al. Metabolic imaging of patients with prostate cancer using hyperpolarized $\left[1{ }^{13} \mathrm{C}\right]$ pyruvate. Sci. Transl. Med. 2013, 5, 198 ra108.

102. Ludwig, C.; Marin-Montesinos, I.; Saunders, M.G.; Günther, U.L. Optimizing the polarization matrix for ex situ dynamic nuclear polarization. J. Am. Chem. Soc. 2010, 132, 2508-2509.

103. Hu, S.; Larson, P.E.; Vancriekinge, M.; Leach, A.M.; Park, I.; Leon, C.; Zhou, J.; Shin, P.J.; Reed, G.; Keselman, P.; et al. Rapid sequential injections of hyperpolarized $\left[1-{ }^{13} \mathrm{C}\right]$ pyruvate in vivo using a sub-kelvin, multi-sample DNP polarizer. Magn. Reson. Imaging 2013, 31, 490-496.

104. Ardenkjær-Larsen, J.H.; Leach, A.M.; Clarke, N.; Urbahn, J.; Anderson, D.; Skloss, T.W. Dynamic nuclear polarization polarizer for sterile use intent. NMR Biomed. 2011, 24, 927-932.

105. Batel, M.; Krajewski, M.; Weiss, K.; With, O.; Däpp, A.; Hunkeler, A.; Gimersky, M.; Pruessmann, K.P.; Boesiger, P.; Meier, B.H.; et al. A multi-sample $94 \mathrm{GHz}$ dissolution dynamic-nuclear-polarization system. J. Magn. Reson. 2012, 214, 166-174.

106. Bornet, A.; Melzi, R.; Perez Linde, A.J.; Hautle, P.; van den Brandt, B.; Jannin, S.; Bodenhausen, G. Boosting dissolution dynamic nuclear polarization by cross polarization. J. Phys. Chem. Lett. 2012, 4, 111-114.

107. Bucur, A.; Reynolds, S.; Kazan, S.; Alizadeh, T.; Port, M.; Tozer, G.M.; Paley, M. Parallel acquisition of hyperpolarized ${ }^{13} \mathrm{C}_{1}$ pyruvate metabolism: Multi-chamber MR compatible bioreactor. Proc. Intl. Soc. Mag. Reson. Med. Salt Lake City 2013, 3951.

108. Cunningham, C.H.; Chen, A.P.; Albers, M.J.; Kurhanewicz, J.; Hurd, R.E.; Yen, Y.F.; Pauly, J.M.; Nelson, S.J.; Vigneron, D.B. Double spin-echo sequence for rapid spectroscopic imaging of hyperpolarized ${ }^{13}$ C. J. Magn. Reson. 2007, 187, 357-362.

109. Cunningham, C.H.; Chen, A.P.; Lustig, M.; Hargreaves, B.A.; Lupo, J.; Xu, D.; Kurhanewicz, J.; Hurd, R.E.; Pauly, J.M.; Nelson, S.J.; et al. Pulse sequence for dynamic volumetric imaging of hyperpolarized metabolic products. J. Magn. Reson. 2008, 193, 139-146. 
110. Larson, P.E.; Kerr, A.B.; Chen, A.P.; Lustig, M.S.; Zierhut, M.L.; Hu, S.; Cunningham, C.H.; Pauly, J.M.; Kurhanewicz, J.; Vigneron, D.B. Multiband excitation pulses for hyperpolarized ${ }^{13} \mathrm{C}$ dynamic chemical-shift imaging. J. Magn. Reson. 2008, 194, 121-127.

111. Larson, P.E.; Bok, R.; Kerr, A.B.; Lustig, M.; Hu, S.; Chen, A.P.; Nelson, S.J.; Pauly, J.M.; Kurhanewicz, J.; Vigneron, D.B. Investigation of tumor hyperpolarized $\left[1-{ }^{13} \mathrm{C}\right]$-pyruvate dynamics using time-resolved multiband RF excitation echo-planar MRSI. Magn. Reson. Med. 2010, 63, 582-591.

112. Larson, P.E.; Hu, S.; Lustig, M.; Kerr, A.B.; Nelson, S.J.; Kurhanewicz, J.; Pauly, J.M.; Vigneron, D.B. Fast dynamic 3D MR spectroscopic imaging with compressed sensing and multiband excitation pulses for hyperpolarized ${ }^{13} \mathrm{C}$ studies. Magn. Reson. Med. 2011, 65, 610-619.

113. Lau, A.Z.; Chen, A.P.; Hurd, R.E.; Cunningham, C.H. Spectral-spatial excitation for rapid imaging of DNP compounds. NMR Biomed. 2011, 24, 988-996.

114. Puckeridge, M.; Pages, G.; Kuchel, P.W. Simultaneous estimation of $\mathrm{T}_{1}$ and the flip angle in hyperpolarized NMR experiments using acquisition at non-regular time intervals. J. Magn. Reson. 2012, 222, 68-73.

115. Frydman, L.; Blazina, D. Ultrafast two-dimensional nuclear magnetic resonance spectroscopy of hyperpolarized solutions. Nat. Phys. 2007, 3, 415-419.

116. Zeng, H.; Lee, Y.; Hilty, C. Quantitative rate determination by dynamic nuclear polarization enhanced NMR of a diels-alder reaction. Anal. Chem. 2010, 82, 8897-8902.

117. Chen, H.Y.; Hilty, C. Hyperpolarized hadamard spectroscopy using flow NMR. Anal. Chem. 2013, 85, 7385-7390.

118. Schröder, L.; Lowery, T.J.; Hilty, C.; Wemmer, D.E.; Pines, A. Molecular imaging using a targeted magnetic resonance hyperpolarized biosensor. Science 2006, 314, 446-449.

119. Bowen, S.; Hilty, C., Time-resolved dynamic nuclear polarization enhanced NMR spectroscopy. Angew. Chem. Int. Ed. Engl. 2008, 47, 5235-5237.

120. Leggett, J.; Hunter, R.; Granwehr, J.; Panek, R.; Perez-Linde, A.J.; Horsewill, A.J.; McMaster, J.; Smith, G.; Köckenberger, W. A dedicated spectrometer for dissolution DNP NMR spectroscopy. Phys. Chem. Chem. Phys. 2010, 12, 5883-5892.

121. Hill, D.K.; Orton, M.R.; Mariotti, E.; Boult, J.K.; Panek, R.; Jafar, M.; Parkes, H.G.; Jamin, Y.; Miniotis, M.F.; Al-Saffar, N.M.; et al. Model free approach to kinetic analysis of real-time hyperpolarized ${ }^{13} \mathrm{C}$ magnetic resonance spectroscopy data. PLoS One 2013, 8, e71996, doi:10.1371/journal.pone.0071996.

(C) 2014 by the authors; licensee MDPI, Basel, Switzerland. This article is an open access article distributed under the terms and conditions of the Creative Commons Attribution license (http://creativecommons.org/licenses/by/3.0/). 